\title{
An English-language adaptation of the Interpersonal Trust Short Scale (KUSIV3)
}

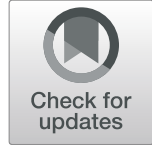

Désirée Nießen ${ }^{1 *}$ (D), Constanze Beierlein ${ }^{2}$, Beatrice Rammstedt ${ }^{1}$ and Clemens M. Lechner ${ }^{1}$

\begin{abstract}
The Interpersonal Trust Short Scale - the English-language adaptation of the Kurzskala Interpersonelles Vertrauen (KUSIV3) - measures interpersonal trust as a psychological disposition with just three items (completion time $\sim 30 \mathrm{~s}$ ). The items of the German-language source version were translated into English using the TRAPD approach. Our empirical validation based on a heterogeneous quota sample in the UK shows that all the reliability coefficients of the English-language adaptation and its correlations with external variables are satisfactory and comparable to those of the German-language source version. Moreover, the results of measurement invariance testing suggest that metric measurement invariance of the scale holds when comparing the UK and Germany, implying the comparability of correlations based on the latent factors across the two nations. As an ultra-short scale, KUSIV3 lends itself to the assessment of interpersonal trust particularly in survey contexts in which assessment time or questionnaire space are limited. It is applicable in a variety of research disciplines, including psychology, sociology, and economics.
\end{abstract}

Keywords: Trust, Interpersonal trust, Attitude, Social interactions, Short scale, Validation

\section{Introduction}

Interpersonal trust is highly relevant in people's everyday lives and in contemporary society as a whole. Thus, studies investigating the functioning of social interactions between single individuals need a valid and-especially in research settings with severe time limitationsefficient measure of interpersonal trust. Motivated by this need, Beierlein, Kemper, Kovaleva, and Rammstedt (2014a) developed an ultra-short-three-item-Germanlanguage measure of interpersonal trust, the Interpersonal Trust Short Scale (German: Kurzskala Interpersonelles Vertrauen; KUSIV3). Because no comparable ultra-short scale for the measurement of interpersonal trust exists for the English-language context, we adapted KUSIV3 to English and thoroughly investigated its psychometric properties of the English-language version using a sample from the United Kingdom (UK).

\footnotetext{
* Correspondence: desiree.niessen@gesis.org

${ }^{1}$ GESIS - Leibniz Institute for the Social Sciences, P.O. Box 1221 55, 68072

Mannheim, Germany

Full list of author information is available at the end of the article
}

\section{Theoretical background}

\section{Interpersonal trust: definition and conceptualization}

Kasperson, Golding, and Tuler (1992) defined trust "as a person's expectation that other persons and institutions in a social relationship can be relied upon to act in ways that are competent, predictable, and caring" (p. 169). To trust means to expect positive outcomes even in the absence of hard evidence suggesting that positive outcomes will occur. Trust is commonly viewed as a vital social lubricant for economic transactions, political processes, and social interactions in general. Since the 1980s, the prerequisites and consequences of trust have been the subject of mounting interest among researchers in the fields of social psychology, political sciences, sociology, economics, and communication studies. However, theoretical conceptualizations of trust both within and across disciplines are diverse (Krampen \& Hank, 2004). Depending on the research focus, the concept may refer either to the trust placed in others (i.e., interpersonal, which is sometimes called "social trust"), the trust placed in political institutions, officials, or the political system as a whole (i.e., political or institutional trust), or both.

(c) The Author(s). 2020 Open Access This article is licensed under a Creative Commons Attribution 4.0 International License, which permits use, sharing, adaptation, distribution and reproduction in any medium or format, as long as you give appropriate credit to the original author(s) and the source, provide a link to the Creative Commons licence, and indicate if changes were made. The images or other third party material in this article are included in the article's Creative Commons licence, unless indicated otherwise in a credit line to the material. If material is not included in the article's Creative Commons licence and your intended use is not permitted by statutory regulation or exceeds the permitted use, you will need to obtain permission directly from the copyright holder. To view a copy of this licence, visit http://creativecommons.org/licenses/by/4.0/. 
Moreover, as we elaborate below, the domain of interpersonal trust also includes a number of different aspects.

During the past 30 years, researchers have demonstrated the predictive value of political and interpersonal trust with regard to such diverse criterion variables as occupational choice, political preferences, outgroup attitudes and discrimination, and political participation and civic involvement (e.g., Wrightsman, 1991). As an essential component of social capital, interpersonal trust is assumed to play a key role in promoting and sustaining viable economies (e.g., Putnam, 1993; Putnam, 1995). Therefore, several studies have addressed the development of trust in today's societies over time. For example, recent studies using U.S. data have reported a decline in social trust over the past decades (e.g., Fairbrother \& Martin, 2013; Twenge, Campbell, \& Carter, 2014).

In his social learning theory of personality, Julian B. Rotter (1971) proposed one of the first and most systematic theoretical descriptions of interpersonal trust, which he defined as "an expectation held by an individual or a group that the word, promise, verbal, or written statement of another individual or group can be relied on" (p. 444). Two types of interpersonal trust are distinguished: generalized trust and limited trust. Generalized trust refers to trust in people who are not known to a person; limited trust refers to trust in persons known to a person, for example, family or friends (OECD, 2017). Because our short scale is dedicated to measuring interpersonal trust in people in general (including strangers but also familiar others), we will use the term "interpersonal trust" in the remainder of this article to denote trust in people who are either known or unknown. We will not explicitly differentiate between generalized and limited trust.

In Krampen's (2000) action-theory model of personality, trust is defined as the expectation that, in many situations, subjectively pleasant outcomes will occur even without action on the part of the individual. Thus, in Krampen's model, trust is linked to situation-outcome expectancies-that is, a person's general expectations that certain events will occur without own action. Viewed as situation-outcome expectancy, interpersonal trust thus refers to the extent to which a person ascribes credibility to other people and expects positive outcomes in the context of social interactions.

\section{Why interpersonal trust matters: evidence on its correlates}

Empirical studies in the social sciences have shown that individual differences in interpersonal trust are systematically related to other variables. For example, interpersonal trust constitutes a resilience factor for mental diseases because it contributes to a person's physical and psychological well-being and reduces the negative impact of social stress (e.g., Omodei \& McLennan, 2000; Takahashi et al., 2005). Furthermore, higher interpersonal trust is associated with a higher level of life and training satisfaction, more optimistic attitudes concerning one's own life (e.g., Koller, 1992; Schweer, 2006), and a lower tendency toward delinquent behaviors (Putnam, 2000). In addition, higher interpersonal trust is associated with a higher likelihood of accepting work systems in which the supervisor has an influence on the extent of workers' remuneration (Kopp \& Schuler, 2003).

With regard to political involvement, interpersonal trust is positively associated with political participation (Sullivan \& Transue, 1999) and social (protest) participation (Benson \& Rochon, 2004). Furthermore, trusters are more likely to attend church (Bègue, 2002) and to be members of social and political organizations (Putnam, 2000). Interpersonal trust is also positively correlated with different aspects of political trust, especially to incumbent trust and modestly related to trust in government (e.g., Schiffman, Thelen, \& Sherman, 2010). Several studies have provided evidence that interpersonal trust is also an important predictor in the field of behavioral economics. For example, interpersonal trust has been found to promote the willingness to lend money (Fetchenhauer \& Dunning, 2009). Additionally, Stadelmann-Steffen and Freitag (2007) found that interpersonal trust promotes economic development in less developed societies.

Finally, the level of interpersonal trust varies among different sociodemographic groups: It decreases with the level of education but increases with age (Krampen, Viebig, \& Walter, 1982) and socio-economic status (Rotter, 1967). Interestingly, and contrary to this, social distrust and social anxiety are positively associated with age and years of education (Krampen et al., 1982). Cross-cultural studies have shown that interpersonal trust is weakly positively associated with individualism (at the collective level) and independent thought and action (at the individual level). For example, Beilmann, Kööts-Ausmees, and Realo (2018) found that "people who emphasize independent thought, action, and readiness to change are also more willing to believe that most people can be trusted and are more engaged in informal social networks" (p. 641). Collectivism is associated with a high prioritization of the group over the self-but this particularly applies to ingroups rather than to outgroups. Therefore, people in collectivist cultures might show a higher level of trust towards relatives and friends, but at the same time, they might endorse a lower level of trust in strangers.

\section{Existing measures of interpersonal trust}

Given its increasing relevance in social science research, measures of interpersonal trust are now included in several large-scale national and international social surveys, 
such as the German Socio-Economic Panel (SOEP), the European Social Survey (ESS), the International Social Survey Programme (ISSP), the British General Household Survey (GHS), the American General Social Survey (GSS), the American National Election Studies (ANES), and the World Values Survey (WVS; e.g., Lundmark, Gilljam, \& Dahlberg, 2016).

The specific measures of interpersonal trust vary across these surveys. As Lundmark et al. (2016) noted, in most surveys (e.g., the GSS, the WVS, and ANES) interpersonal trust is assessed using a single, fully balanced question-"Generally speaking, would you say that most people can be trusted or that you need to be very careful in dealing with people?" (p. 26)-accompanied by a dichotomous scale with the alternatives You can't be too careful (1) and Most people can be trusted (2). In contrast, some surveys (e.g., ESS, SOEP) measure interpersonal trust using between one and three Likert-type items with multiple response categories. Employing a randomized experimental design, Lundmark et al. (2016) compared these different approaches and concluded that interpersonal trust was best measured with multiple response categories rather than a dichotomous scale because "using a several-point scale provides a more valid as well as a more substantively detailed measurement" (p. 40; for general recommendations for measuring attitudes and values, see also Krosnick \& Fabrigar, 1997). Survey items measuring interpersonal trust using scales with multiple response categories are often based on earlier measures of interpersonal trust, such as Rotter's (1967) Interpersonal Trust Scale (ITS). The ITS as a whole or selected items of the ITS have been translated into a number of languages (e.g., a German full version was developed by Amelang, Gold, \& Kübel, 1984; single items were translated into Chinese, e.g., Liu, Rau, \& Wendler, 2015). The ITS uses a Likert-type scale that comprises 25 negatively and positively poled items tapping, among other dimensions, interpersonal trust. However, there is an ongoing debate on whether or not measurement equivalence can be assumed when using the interpersonal trust measures applied in large-scale social surveys, such as the ESS (see, e.g., Reeskens \& Hooghe, 2008; van der Veld \& Saris, 2011). Additionally, questions about interpersonal trust may have different meanings in different social groups and, thus, show nonequivalence (Bulloch, 2013). Moreover, some of the existing (short) measures for (generalized) interpersonal trust tap into different aspects of the construct simultaneously without taking into account this potential multidimensionality. For example, the German SOEP-trust scale (Naef \& Schupp, 2009) includes one specific item measuring trust in strangers, rather than assessing interpersonal trust as a whole. Thus, these scales may lack conceptual clarity. Hence, there is an unmet need for a conceptually coherent, valid, reliable, and crossculturally equivalent-yet short and broadly applicablemeasure of interpersonal trust. The scale presented in this article aims to meet this need.

\section{Scale development}

To develop the German-language source version of KUSIV3, Beierlein, Kemper, et al. (2014a) drew on items from existing social science surveys and interpersonal trust scales, such as SOEP-trust (Naef \& Schupp, 2009). Some of these items were linguistically revised. The (revised) items were then tested using exploratory factor analysis (EFA). In the further construction process, the authors discarded items that measured domain-specific rather than interpersonal trust as a whole (for more detailed information, see Beierlein, Kemper, et al., 2014a). The German-language KUSIV3 was thoroughly validated based on a comprehensive sample representative of the adult population in Germany in terms of age, gender, and educational attainment.

Because researchers may be interested in comparing the level of interpersonal trust between different societies, there is a need for a cross-culturally valid measure. To enhance the scope of application of KUSIV3 and to enable social surveys to use KUSIV3 in an English-language context, the scale was adapted to the English language (by Beierlein, Kemper, et al., 2014a) and validated in a sample from the UK (in the present study). First, the three items of KUSIV3 were adapted to English by translating the items following the TRAPD approach (Translation, Review, Adjudication, Pretesting, and Documentation; Harkness, 2003). Two professional translators (English native speakers) translated the instruction, the item wordings, and the response scale labels independently of each other into British English and American English, respectively. During the translation process, none of the translators met any problems or difficulties. Thus, none of the items was flagged as potentially problematic. There were only slight differences in the two separate translation outcomes. Second, an adjudication meeting was held where psychological experts, the two translators, and an expert in questionnaire translation reviewed the various translation proposals and developed the final translation. In collaboration with the team of researchers, the translators quickly came to a consensus and agreed upon an optimal translation of all elements of the scale.

The source instrument by Beierlein, Kemper, et al. (2014a) was developed in and validated for the German language. The aim of the present study was to empirically investigate different types of evidence for the validity of the English-language adaptation of KUSIV3 and to directly compare its psychometric properties with those of the German-language source version. 


\section{Method}

\section{Samples}

To investigate the psychometric properties of the English-language adaptation of KUSIV3, and their comparability with those of the German-language source instrument, we assessed both versions in a web-based survey (using computer-assisted self-administered interviewing [CASI]) conducted in the UK and Germany (DE) by the online access panel provider respondi AG. Fielding took place in January 2018. For both the UK and Germany, quota samples were drawn that represented the heterogeneity of the adult population with regard to age, gender, and educational attainment. Only native speakers of the respective languages were recruited. We explained our research goal (investigation of the quality of several questionnaires) to the participants. Respondents were financially rewarded for their participation. In both states, a subsample was reassessed after approximately 3 to 4 weeks (median time intervals: 28 days in the UK and 20 days in Germany).

Only respondents who completed the full questionnaire-that is, who did not abort the survey prematurely-were included in our analyses. To handle missing values on single items, we used full information maximum likelihood estimation (FIML) in our analyses. The gross sample sizes were $N_{\mathrm{UK}}=508$ and $N_{\mathrm{DE}}=513$. In the next step, invalid cases were excluded based on (a) ipsatized variance-that is, the within-person variance across items (Kemper \& Menold, 2014)-if the person fell within the lower $5 \%$ of the sample distribution of ipsatized variance; (b) the Mahalanobis distance of a person's response vector from the average sample response vector (Meade \& Craig, 2012) if he or she fell within the upper $2.5 \%$ of the sample distribution of the Mahalanobis distance; and (c) response time, namely, if the person took, on average, less than $1 \mathrm{~s}$ to respond to an item. Our intention in choosing relatively liberal cutoff values was to avoid accidentally excluding valid cases and thereby creating a systematic bias in our data. All exclusion criteria were applied simultaneously, that is, any respondent who violated one or more of the three criteria was excluded from the analyses and that only those who met all three criteria were included. This approach resulted in total exclusion of 40 cases (7.9\%) in the UK subsample and of 39 cases (7.6\%) in the German subsample, yielding net sample sizes of $N_{\mathrm{UK}}=468$ (retest: $N_{\mathrm{UK}}=111$ ) and $N_{\mathrm{DE}}=474$ (retest: $N_{\mathrm{DE}}=117$ ). Table 1 depicts in detail the sample characteristics and their distribution.

\section{Material}

Online surveys were conducted in German for the German sample and in English for the UK sample. The surveys comprised the respective language versions of
Table 1 Sample characteristics

\begin{tabular}{lll}
\hline & UK & Germany \\
\hline$N$ & 468 & 474 \\
Mean age in years (SD) [range] & $45.2(14.5)$ [18-69] & 44.0 (14.4) [18-69] \\
$\begin{array}{l}\text { Proportion of women (\%) } \\
\text { Educational level (\%) }\end{array}$ & 52.6 & 50.0 \\
$\begin{array}{l}\text { Low: never went to school, } \\
\text { skills for life/1-4 GCSEs A*-C }\end{array}$ & 34.8 & 33.5 \\
$\begin{array}{l}\text { or equivalent } \\
\text { Intermediate: } 5 \text { or more }\end{array}$ & 32.1 & \\
$\begin{array}{l}\text { GCSEs A*-C/vocational } \\
\text { GCSE/GNVQ intermediate or } \\
\text { equivalent }\end{array}$ & & 33.8 \\
$\begin{array}{l}\text { High: } 2 \text { or more A-levels or } \\
\text { equivalent }\end{array}$ & 33.1 & 32.7 \\
\hline
\end{tabular}

Note. The equivalent German educational levels were as follows (from low to high): ohne Bildungsabschluss/Hauptschule [no educational qualification; lower secondary leaving certificate]; mittlerer Schulabschluss [intermediate school leaving certificate]; and (Fach-)Hochschulreife [higher education entrance qualification]

KUSIV3, alongside sociodemographic characteristics and a range of external criteria.

KUSIV3 consists of three items measuring the construct interpersonal trust. The English-language adaptations of these items are displayed in Table 2 and in Additional File 1 in the Supplementary Online Material (for the original German-language items, see Additional File 2 in the Supplementary Online Material and Beierlein, Kemper, et al., 2014a). As in the German-language source instrument, item 1 and item 3 are positively worded in relation to the underlying construct and item 2 is negatively worded. Items are answered using a fivepoint rating scale ranging from do not agree at all (1), over hardly agree (2), somewhat agree (3), and mostly agree (4) to completely agree (5). The negatively keyed item is reverse-scored (6 - raw score), and the unweighted mean score of the three items is computed to obtain an interpersonal trust scale score. ${ }^{1}$ In doing so, we treated the ordinal Likert response format as continuous.

Although the measure is, strictly speaking, ordinal in nature, previous studies have shown that such rating scales can be treated as interval, and hence, continuous data without incurring major bias (see also, e.g., Carifio \& Perla, 2007; Norman, 2010). Moreover, as the

\footnotetext{
${ }^{1}$ We suggest that individual answers should be aggregated to the scale level only if there are no missing values on any of the three items-a recommendation that is followed in the present study, also with respect to other constructs used for the validation. If there are missing values on one or more items, researchers should use appropriate methods for handling missing data, such as multiple imputation or full information maximum likelihood estimation (see Rose, Wagner, Mayer, \& Nagengast, 2019, for an application of maximum likelihood estimation to computing manifest scale scores in a latent variable framework).
} 
Table 2 Items of the English-language adaptation of KUSIV3

\begin{tabular}{lll}
\hline No. & Item & Polarity \\
\hline 1 & I am convinced that most people have good intentions. \\
2 & You can't rely on anyone these days. \\
3 & In general, people can be trusted. \\
\hline Note. The instructions are as follows: "In the following we are interested in \\
your attitude towards other people. Please indicate the extent to which you \\
agree or disagree with each of the statements below."
\end{tabular}

simulation studies conducted by Rhemtulla, BrosseauLiard, and Savalei (2012) show, the consequences of treating ordinal items as linear (continuous) are typically minor with maximum likelihood estimation producing "estimates within the range of acceptable bias" (p. 370; and it does not make any difference to the findings) when five or more response categories are used, these categories can be assumed to be approximately equidistant, and these variables are approximately normally distributed. In our case, the underlying construct can be seen as continuous (the frequency distribution of the KUSIV3 items and scale score is displayed in Figure S1S2 in Additional File 3 in the Supplementary Online Material indicating an approximately normally distributed answering distribution) and the distance between the single answering categories as approximately equidistant. We used a maximum likelihood estimator with robust standard errors (MLR) that also accounts for nonnormality in the items' distributions.

To examine evidence based on the relationship between scores on KUSIV3 and scores on (a) the Big Five dimensions of personality, (b) general self-efficacy, (c) locus of control, (d) optimism-pessimism, (e) life satisfaction, (f) political efficacy, (g) political preferences, (h) socially desirable responding, and (i) health, respectively, the following short scale measures were also administered as part of the survey:

a) The extra-short form of the Big Five Inventory-2 (BFI2-XS; English version: Soto \& John, 2017; German version: Rammstedt, Danner, Soto, \& John, 2020)

b) The General Self-Efficacy Short Scale-3 (GSE-3; Doll, Nießen, Schmidt, Rammstedt, \& Lechner, 2020; German version: Allgemeine Selbstwirksamkeit Kurzskala; ASKU; Beierlein, Kovaleva, Kemper, \& Rammstedt, 2014)

c) The Internal-External Locus of Control Short Scale-4 (IE-4; Nießen, Groskurth, Rammstedt, \& Lechner, 2020b; German version: InternaleExternale-Kontrollüberzeugung-4; Kovaleva, Beierlein, Kemper, \& Rammstedt, 2014)

d) The Optimism-Pessimism Short Scale-2 (SOP2; Nießen, Groskurth, Kemper, Rammstedt, \& Lechner, 2020; German version: Skala Optimismus-
Pessimismus-2; Kemper, Beierlein, Kovaleva, \& Rammstedt, 2014)

e) The General Life Satisfaction Short Scale (L-1; Nießen, Groskurth, Rammstedt, \& Lechner, 2020a; German version: Kurzskala zur Erfassung der Allgemeinen Lebenszufriedenheit; Beierlein, Kovaleva, László, Kemper, \& Rammstedt, 2015)

f) The Political Efficacy Short Scale (PESS; Groskurth, Nießen, Rammstedt, \& Lechner, 2020; German version: Political Efficacy Kurzskala; PEKS; Beierlein, Kemper, Kovaleva, \& Rammstedt, 2014b)

g) The political Left-Right Self-Placement scale (English and German version: Breyer, 2015)

h) The Social Desirability-Gamma Short Scale (KSEG; Nießen, Partsch, Kemper, \& Rammstedt, 2019; German version: Kurzskala Soziale ErwünschtheitGamma; Kemper, Beierlein, Bensch, Kovaleva, \& Rammstedt, 2014)

i) The single-item question used in the ESS to measure self-reported general health (ESS, 2016)

In addition, a set of sociodemographic variables (gender, age, highest level of education, income, and employment status) was collected.

\section{Results}

To empirically examine the English-language adaptation of KUSIV3 and to investigate its comparability with the German-language source version, we analyzed psychometric criteria-more precisely, objectivity, reliability, and validation evidence-in both language versions. Moreover, we assessed test fairness across both states via measurement invariance tests. The statistical analysis was run with $\mathrm{R}$; the code can be found in Additional File 4 in the Supplementary Online Material.

\section{Descriptive statistics and reference ranges}

In the first step, we analyzed the descriptive statistics and reference ranges separately for both versions of KUSIV3. Table 3 shows the means, standard deviations, skewness, and kurtosis for the three items separately for the English and German samples. The inter-item correlations are as follows: $\mathrm{UK}-r_{12}=.34, r_{13}=.62, r_{23}=.28$; $\mathrm{DE}-r_{12}=.36, r_{13}=.67, r_{23}=.43$. Additional File 5 : Table S1 in the Supplementary Online Material provides the reference ranges in terms of means, standard deviations, skewness, and kurtosis of the KUSIV3 scale scores for the total population, as well as separately for gender and age groups in both states.

\section{Objectivity}

A scale can be regarded as objective when it works (a) independently of the administrator (objectivity of application), (b) independently of the evaluator of the test 
Table 3 Descriptive statistics for the KUSIV3 items

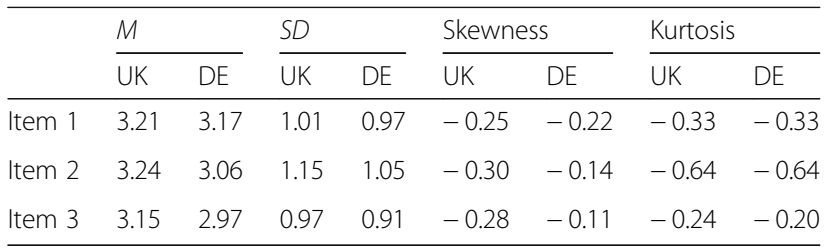

Note. UK = United Kingdom $(N=468), \mathrm{DE}=$ Germany $(N=474)$

(objectivity of evaluation), and (c) when unambiguous and user-independent rules are provided (objectivity of interpretation). The standardized questionnaire format and written instructions, the fixed scoring rules and labeled categories, and the reference ranges ensured the objectivity of the application, evaluation, and interpretation of KUSIV3.

\section{Reliability}

As estimates for the reliability of KUSIV3, we computed Cronbach's alpha (Cronbach, 1951), McDonald's omega (McDonald, 1999; Raykov, 1997), and the test-retest stability. The rationale for using these measures was twofold. First, we wanted to provide information on the most commonly used reliability estimate, namely Cronbach's alpha, although the appropriateness of this measure of internal consistency is limited in the case of ultrashort scales, where items are selected to reflect the bandwidth of the underlying dimension (i.e., its heterogeneity but not its homogeneity). Second, because we specified a tau-congeneric model, we also report McDonald's omega, as it is a more appropriate measure than Cronbach's alpha in the current context.

The reliability estimates for KUSIV3 ranged between .67 and .78 (UK) and .73 and .79 (DE), which can be deemed sufficient for research purposes (Aiken \& Groth-Marnat, 2006; Kemper, Trapp, Kathmann, Samuel, \& Ziegler, 2019). As often occurs with (ultra-)short scales, test-retest reliability (UK: $r_{t t}=.78$; DE: $r_{t t}=.79$ ) was higher than internal consistency (UK: $\alpha=.67, \omega=$ .69; DE: $\alpha=.73, \omega=.75)$. In detail, KUSIV3 proved to be slightly more reliable in Germany than in the UK (except in the case of test-retest stability). Because internal consistency estimates vary across groups, test-retest correlations are recommended for a comparison of the reliability of scale scores.

\section{Validity}

Besides content-related evidence, which was provided by Beierlein, Kemper, et al. (2014a) during the original scale development process, we investigated two types of validation evidence: evidence based on the internal structure of the scale and evidence based on the relationship between scores on the scale and on other variables.
We first investigated the factorial structure of KUSIV3 in the UK and Germany in two separate confirmatory factor analyses (CFA). Afterwards, we subsequently conducted multiple-group confirmatory factor analyses (MGCFA) using a unidimensional measurement model developed for Germany by Beierlein, Kemper, et al. (2014a) with one latent factor capturing interpersonal trust. In both the UK and Germany, factor loadings and item intercepts were freely estimated, whereas the variance of the latent interpersonal trust factor was set to 1 . We used a MLR estimation. The model is plotted in Fig. 1. A latent measurement model with only three items and no further restrictions (e.g., equality restrictions on the loadings) is just-identified and has zero degrees of freedom. Therefore, it calculates the closed-form solution for the parameters. Only a multi-group model with equivalence restrictions provides an interpretable model fit (see section international equivalence). Even though the factor loadings of item 2, which is negatively keyed, are lower than the loadings of the other two positively keyed items, the size of the items' factor loadings is consistent with a unidimensional measurement model (see Fig. 1) and gives a first indication of the internal structure of the scale. That negatively worded items show larger loadings than positively worded ones is a frequently observed pattern (e.g., Lechner, Danner, \& Rammstedt, 2019; Weijters, Baumgartner, \& Schillewaert, 2013) that could be caused, for example, by acquiescence, a response style that causes negative loadings to be weaker than they would otherwise be (e.g., Lechner, Partsch, Danner, \& Rammstedt, 2019; Lechner \& Rammstedt, 2015).

Evidence based on the relationship between scores on KUSIV3 and on other variables was computed based on manifest correlations. We preferred manifest correlations over latent ones in order to remain consistent (some correlates, such as age and gender, do not have measurement errors) and to be able to compare the single effect sizes with each other. Therefore, the reported values probably represent the lower bound of the true associations. The correlation coefficients are depicted in Table 4; their interpretation is based on Cohen (1992): small effect $(r \geq .10)$, medium effect $(r \geq .30)$, and strong effect $(r \geq .50)$. Due to alpha accumulation through multiple testing, only coefficients with a significance level above $p<.001$ are interpreted (this is the threshold after Bonferroni adjustment-we use adjusted significance levels only to decide which significant correlations should be used for interpretation; Table 4 displays unadjusted $p$ values). Before computing the correlations, we recoded item 2 and the health variable.

In order to investigate this type of evidence, we correlated KUSIV3 with the following constructs and criteria: (a) the Big Five dimensions Extraversion, Agreeableness, Conscientiousness, Emotional Stability, and Openness 


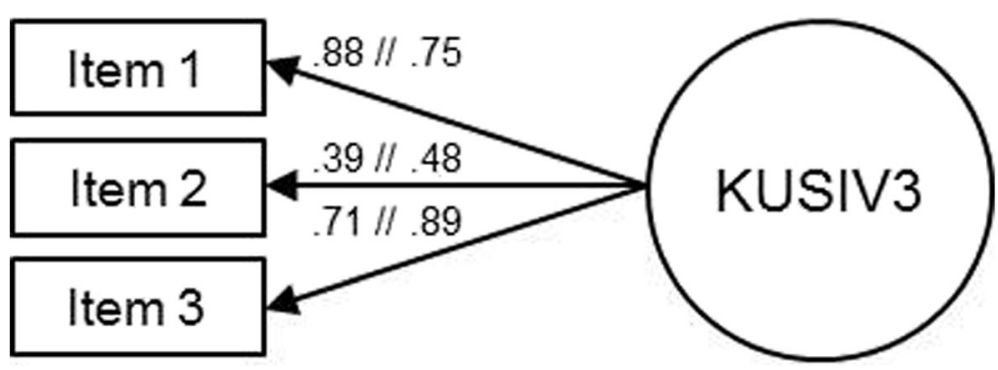

Fig. 1 Unidimensional measurement model of KUSIV3 with standardized coefficients. The negatively keyed item is reverse-scored. The coefficients of the German sample are presented after the double slash. Item error terms are omitted for clarity. $N_{U K}=468 ; N_{D E}=474$

Table 4 Correlations of KUSIV3 with relevant variables

\begin{tabular}{|c|c|c|c|c|}
\hline & \multicolumn{2}{|c|}{ UK } & \multicolumn{2}{|c|}{$\mathrm{DE}$} \\
\hline & $r$ & $\mathrm{Cl}_{95 \%}$ & $r$ & $\mathrm{Cl}_{95 \%}$ \\
\hline \multicolumn{5}{|l|}{ Big Five } \\
\hline Extraversion & $.16^{* * *}$ & {$[.07, .25]$} & .06 & {$[-.03, .15]$} \\
\hline Agreeableness & $.37^{* * *}$ & {$[.29, .45]$} & $.36^{* * *}$ & {$[.28, .44]$} \\
\hline Conscientiousness & .03 & {$[-.06, .12]$} & .06 & {$[-.03, .15]$} \\
\hline Emotional Stability & $.32^{* * *}$ & {$[.40, .24]$} & $.30 * * *$ & {$[.38, .22]$} \\
\hline Openness & .08 & {$[-.01, .17]$} & .04 & {$[-.05, .13]$} \\
\hline General self-efficacy & $.10^{*}$ & {$[.01, .19]$} & $.17^{* * *}$ & {$[.08, .26]$} \\
\hline \multicolumn{5}{|l|}{ Locus of control } \\
\hline Internal & $.16^{* * *}$ & {$[.08, .25]$} & $.16^{* * *}$ & {$[.07, .24]$} \\
\hline External & -.06 & {$[-.15, .04]$} & $-.22 * * *$ & {$[-.30,-.13]$} \\
\hline Optimism-pessimism & $.42^{* * *}$ & {$[.35, .49]$} & $.43^{* * *}$ & {$[.35, .50]$} \\
\hline \multicolumn{5}{|l|}{ Political efficacy } \\
\hline Internal & $.17^{* * *}$ & {$[.08, .25]$} & $.10^{*}$ & {$[.01, .19]$} \\
\hline External & $.16^{* * *}$ & {$[.08, .25]$} & $.28^{* * *}$ & {$[.20, .37]$} \\
\hline Left-right self-placement & -.10 & {$[-.21, .01]$} & $-.25^{* * *}$ & {$[-.34,-.15]$} \\
\hline \multicolumn{5}{|l|}{ Social desirability } \\
\hline Exaggerating positive qualities & $.24 * * *$ & {$[.16, .33]$} & $.17^{* * *}$ & {$[.08, .25]$} \\
\hline Minimizing negative qualities & .02 & {$[-.07, .11]$} & $-.13^{* *}$ & {$[-.21,-.04]$} \\
\hline Life satisfaction & $.41^{* * *}$ & {$[.33, .48]$} & $.35^{* * *}$ & {$[.27, .43]$} \\
\hline Health & $.24^{* * *}$ & {$[-.32,-.15]$} & $.18^{* * *}$ & {$[-.27,-.09]$} \\
\hline \multicolumn{5}{|l|}{ Sociodemographic characteristics } \\
\hline Employment status & -.03 & {$[-.12, .06]$} & -.06 & {$[-.15, .03]$} \\
\hline Income & $.15^{* *}$ & {$[.06, .24]$} & $.20 * * *$ & {$[.11, .29]$} \\
\hline Educational level & $.11^{*}$ & {$[.01, .19]$} & .09 & {$[.00, .17]$} \\
\hline Age & $.17^{* * *}$ & {$[.08, .25]$} & $.13^{* *}$ & {$[.04, .22]$} \\
\hline Gender & $-.12^{* *}$ & {$[-.12,-.03]$} & .01 & {$[-.08, .10]$} \\
\hline
\end{tabular}


assessed with the BFI-2-XS (Rammstedt et al., 2020; Soto \& John, 2017); (b) general self-efficacy assessed with GSE-3 (Doll et al., 2020)/ASKU (Beierlein, Kovaleva, et al., 2014); (c) internal and external locus of control assessed with the IE-4 (Kovaleva et al., 2014; Nießen, Groskurth, Rammstedt, et al., 2020b); (d) optimism and pessimism assessed with SOP2 (Kemper, Beierlein, Kovaleva, et al., 2014; Nießen, Groskurth, Kemper, et al., 2020); (e) general life satisfaction assessed with L-1 (Beierlein et al., 2015; Nießen, Groskurth, Rammstedt, et al., 2020a); (f) internal and external political efficacy assessed with PESS (Groskurth et al., 2020)/PEKS (Beierlein, Kemper, et al., 2014b); (g) political preferences assessed with the Left-Right Self-Placement scale (Breyer, 2015); (h) socially desirable responding assessed with the KSE-G (Kemper, Beierlein, Bensch, et al., 2014; Nießen et al., 2019); and (i) self-reported general health measured with the single-item question used in the ESS.

\section{Correlations with convergent and discriminant constructs}

With regard to personality in terms of the Big Five dimensions, previous research suggests strongest associations of interpersonal trust with Agreeableness (see also Evans \& Revelle, 2008; Omodei \& McLennan, 2000; Perunovic, 2008), which supports the notion that trust is a facet of the Agreeableness dimension (e.g., Costa, McCrae, \& Dye, 1991). In addition, strong positive associations with Emotional Stability have been consistently reported (see also Evans \& Revelle, 2008; Halamandaris \& Power, 1997; Omodei \& McLennan, 2000). For the German-language version of KUSIV3, initial findings by Beierlein, Kemper, et al. (2014a) replicate these associations. In the present analyses, too, strong positive relations of KUSIV3 with Agreeableness and Emotional Stability were found for both the UK and Germany and thus for both language versions. Partly in line with previous findings (Beierlein, Kemper, et al., 2014a; Evans \& Revelle, 2008; Halamandaris \& Power, 1997), we also found a small but substantial positive association of interpersonal trust with Extraversion, but only for the UK. However, unlike Beierlein, Kemper, et al. (2014a), who found small positive associations of Openness and Conscientiousness with interpersonal trust, we found zero correlations for both the UK and Germany.

With regard to internal locus of control, optimismpessimism, and external political efficacy, we could replicate the findings of the German-language source version: Consistent with previous findings, including those of Beierlein, Kemper, et al. (2014a), we found-for both the UK and Germany-stable small-to-medium positive relations with internal locus of control (e.g., Massari \& Rosenblum, 1972; Stimpson \& Maughan, 1978), optimism (e.g., Mealy, Stephan, Mhaka-Mutepfa, \&
Alvadoro-Sanchez, 2015; Schweer, 2006), and external political efficacy (e.g., Koller, 1992; Schiffman et al., 2010; Schyns \& Koop, 2010). Individuals high in optimism and external political efficacy had a higher propensity for interpersonal trust. Concerning general selfefficacy and external locus of control, we could fully support the findings for the German-language source version; for internal political efficacy, we could do so only for the English-language adaptation: In the German sample, there was a small positive effect for general selfefficacy (see also Munir et al., 2016) and a small negative effect for external locus of control (see Thurber \& Friedli, 1976), whereas in the UK sample there were zero or no reportable correlations. In contrast, there was a small positive effect for internal political efficacy in the UK sample but no reportable correlation in the German sample. In line with Rotter $(1967,1971)$, there was a small positive association with socially desirable responding in both samples, but only for the "exaggerating positive qualities" subscale, which depicts the selfdeceptive enhancement component of communioninduced socially desirable responding (Nießen et al., 2019). Even though we found-among others-partially different correlations in both states, in sum, the pattern of correlations suggests evidence based on scale-construct relationships.

\section{Correlations with concurrent criteria}

Concerning life satisfaction and health, we could replicate the findings of Beierlein, Kemper, et al. (2014a): In line also with other previous findings, we found in both the UK and DE samples stable small-to-medium positive associations with life satisfaction (e.g., Barefoot et al., 1998; Jovanović, 2016) and health (e.g., Barefoot et al., 1998; Feng, Vlachantoni, Liu, \& Jones, 2016; Schneider, Konijn, Righetti, \& Rusbult, 2011). Individuals who reported greater life satisfaction and better general health had a higher propensity for interpersonal trust. In addition, we found a negative relation between interpersonal trust and political left-right self-placement (DE only). Individuals who placed themselves more on the left of the political spectrum had a higher propensity for interpersonal trust, and those who placed themselves more on the right of the spectrum had a lower propensity for interpersonal trust. This is in line with evidence from Krampen et al. (1982) that conservatism is related more to social distrust. Despite these contrary results concerning political selfplacement, the pattern of correlations suggests evidence based on scale-criterion relationships in view of the findings on life satisfaction and health.

\section{Correlations with sociodemographic characteristics}

We calculated correlations between KUSIV3 and relevant sociodemographic characteristics, namely employment 
status, income, educational level, age, and gender. In the present analyses, we found small positive correlations between interpersonal trust and income (DE only) and age (UK only). Individuals with a higher income (DE only) and elderly individuals (UK only) had a greater propensity for interpersonal trust. The first-mentioned finding is in line with evidence from Bulloch (2010) that interpersonal trust increases with a higher income; the latter finding is in line with evidence from Bulloch (2010) and Krampen et al. (1982) that interpersonal trust increases with age. There were no associations between interpersonal trust and employment status, and no reportable associations between interpersonal trust and educational level (unlike Bulloch, 2010; Krampen et al., 1982), gender (unlike Bulloch, 2013; Zinchenko, Zotova, \& Tarasova, 2017), age (DE only), and income (UK only).

\section{International equivalence}

We assessed international equivalence across the UK and Germany via measurement invariance tests with MG-CFA (Vandenberg \& Lance, 2000; Widaman \& Reise, 1997). As mentioned above, the configural model has zero degrees of freedom; therefore, no misfit can occur. In order to determine the level of measurement invariance, we used the cut-off values recommended by Chen (2007). According to these benchmarks, SRMR as well as MLR-scaled CFI and RMSEA indicate that metric measurement invariance of KUSIV3 holds across the UK and Germany, implying comparability of correlations based on the latent factors between both states (metric model: CFI [comparative fit index] $=.994$, RMSEA [root mean square error of approximation] $=.046$, SRMR $=$ .021 ; scalar model: $\mathrm{CFI}=.977$, RMSEA $=.067$, SRMR $=$ .031; the fit indices refer to the commonly used MLRscaled CFI and RMSEA, which-strictly speaking-apply only to populations). ${ }^{2}$ Full scalar invariance does not hold, but partial scalar invariance holds by setting the intercept of item 1 free $(\mathrm{CFI}=.994$, RMSEA $=.039$, SRMR $=.023){ }^{3}$ which implies that latent means can be directly compared.

\section{Discussion and conclusion}

The aim of the present study was to empirically assess different types of evidence for the validity of the Interpersonal Trust Short Scale, an English-language adaptation of the Kurzskala Interpersonelles Vertrauen (Beierlein, Kemper, et al., 2014a). The ultra-short scale measuring interpersonal trust as a psychological

\footnotetext{
${ }^{2}$ Taking the sample size into account prevents biased fit indices and yields so-called robust CFI and robust RMSEA values in R/lavaan (Brosseau-Liard \& Savalei, 2014; Brosseau-Liard, Savalei, \& Li, 2012): metric model-robust CFI $=.996$, robust RMSEA $=.055$; scalar model-robust CFI $=.985$, robust RMSEA $=.074$.

${ }^{3}$ Robust CFI $=.996$, robust RMSEA $=.045$.
}

disposition was constructed for use in assessment settings with severe time limitations, such as large-scale surveys. Our results-based on two comprehensive samples representing the heterogeneity of the adult populations in the UK and Germany-reveal, first, that the English-language version of KUSIV3 is also a reliable, valid, and useful instrument for measuring interpersonal trust. Second, our findings reveal that the psychometric properties of the English-language adaptation of KUSIV3 are also comparable to those of the German-language source version.

In detail, the estimates for reliability indicate that the scale scores for the English-language adaptation are acceptable and comparable to those for the Germanlanguage source version. Furthermore, the results of measurement invariance testing suggest metric measurement invariance of the scale, thereby implying comparability of correlations based on the latent factors across the UK and Germany. The factor loading patterns in both language versions show that factor loadings were lower only for the negatively keyed item in the scale. However, given the small number of items, we did not control for this potential method effect in our measurement model. Furthermore, as measurement invariance testing could not confirm scalar invariance, it would be necessary to test more closely the comparability of the KUSIV3 scale scores across gender and age groups. Due to the limited size of subgroups in our sample, we refrained from analyzing differences between subgroups.

Also with regard to the scale's convergent and discriminant construct and criterion validity, we could partly support the findings of the original validation of the German-language source version (Beierlein, Kemper, et al., 2014a): For both the UK and Germany, we found the strongest correlations with optimism, life satisfaction, and the Big Five dimensions Agreeableness and Emotional Stability. Individuals who were high in optimism, life satisfaction, Agreeableness, and Emotional Stability had a tendency to have higher levels of interpersonal trust. Our data yielded only a few differences between the validity coefficients of the German-language source version and the adapted English-language version (e.g., with regard to the scales' correlations with external control beliefs). Further studies could investigate these differences in more detail, for example by testing the impact of cross-cultural differences on the relationship between the constructs.

The scope of our study was limited in several ways. First, our samples were restricted to participants in a web-based survey (CASI). Hence, we cannot generalize our findings to the population as a whole, including, for example, persons who are not computer literate. Second, our validation of the English-language KUSIV3 was restricted to the population of the UK only. As a 
consequence, the results are not automatically generalizable to other English-speaking populations, for example, in the United States. Future studies should address these limitations.

In sum, the results of the present study show for the first time the utility of the English-language adaptation of KUSIV3 and the comparability of its psychometric properties with those of the German-language source version. Researchers in English-speaking countries now have the possibility of measuring interpersonal trust in settings with severe time limitations. The scale is recommended for use in self-report surveys in the social sciences and, therefore, for research purposes onlyespecially when measuring behavior, personality characteristics, and attitudes.

\section{Supplementary information}

Supplementary information accompanies this paper at https://doi.org/10. 1186/s42409-020-00016-1.

Additional file 1: Answer Sheet (English Version) KUSIV3

Additional file 3: Figure S1-S2. Frequency distribution of the answering categories of the KUSIV3 items and scale score

Additional file 4: $\mathrm{R}$ Code for Analysis

Additional file 5: Table S1. Reference Ranges of the KUSIV3 Scale Scores for the Total Population and Separately for Gender and Age Groups

\section{Abbreviations}

ANES: American National Election Studies; ASKU: Allgemeine Selbstwirksamkeit Kurzskala; BFI-2-XS: Extra-short form of the Big Five Inventory-2; CASI: Computer-assisted self-administered interviewing; CFA: Confirmatory factor analysis; CFI: Comparative fit index; DE: Germany; EFA: Exploratory factor analysis; ESS: European Social Survey; FIML: Full information maximum likelihood; GHS: General Household Survey; GSE3: General Self-Efficacy Short Scale-3; GSS: General Social Survey; IE4: Internal-External Locus of Control Short Scale-4/Internale-ExternaleKontrollüberzeugung-4; ISSP: International Social Survey Programme; ITS: Interpersonal Trust Scale; KSE-G: Social Desirability-Gamma Short Scale/ Kurzskala Soziale Erwünschtheit-Gamma; KUSIV3: Interpersonal Trust Short Scale/Kurzskala Interpersonelles Vertrauen; L-1: General Life Satisfaction Short Scale/Kurzskala zur Erfassung der Allgemeinen Lebenszufriedenheit; MGCFA: Multiple-group confirmatory factor analysis; MLR: Maximum likelihood with robust standard errors; PEKS: Political Efficacy Kurzskala; PESS: Political Efficacy Short Scale; RMSEA: Scaled root mean square error of approximation; SOEP: German Socio-Economic Panel; SOP2: Optimism-Pessimism Short Scale-2/Skala Optimismus-Pessimismus-2; SRMR: Standardized root mean square residual; TRAPD: Translation, Review, Adjudication, Pretesting, and Documentation; UK: United Kingdom; WVS: World Values Survey

\section{Acknowledgements}

We would like to thank Melanie Partsch and Katharina Groskurth from GESIS - Leibniz Institute for the Social Sciences for preparing the data.

\section{Authors' contributions}

All authors read and approved the final manuscript.

\section{Funding}

The study was funded by an internal grant provided by GESIS - Leibniz Institute for the Social Sciences, Mannheim, Germany.

\section{Availability of data and materials}

The dataset supporting the conclusions of this article is available in the GESIS datorium repository, https://doi.org/10.7802/1861.

\section{Competing interests}

The authors declare that they have no competing interests to disclosure.

\section{Author details}

${ }^{1}$ GESIS - Leibniz Institute for the Social Sciences, P.O. Box 1221 55, 68072 Mannheim, Germany. ${ }^{2}$ Hochschule Hamm-Lippstadt (HSHL), Hamm,

Germany.

Received: 17 July 2019 Accepted: 4 August 2020

Published online: 17 November 2020

\section{References}

Aiken, L. R., \& Groth-Marnat, G. (2006). Psychological testing and assessment (12th ed.). Boston, MA: Pearson.

Amelang, M., Gold, A., \& Kübel, E. (1984). Über einige Erfahrungen mit einer deutschsprachigen Skala zur Erfassung des zwischenmenschlichen Vertrauens (Interpersonal Trust) [Experiences with a German-language scale for the measurement of interpersonal trust]. Diagnostica, 30, 198-215.

Barefoot, J. C., Maynard, K. E., Beckham, J. C., Brummett, B. H., Hooker, K., \& Siegler, I. C. (1998). Trust, health, and longevity. Journal of Behavioral Medicine, 21, $517-526$.

Bègue, L. (2002). Beliefs in justice and faith in people: Just world, religiosity and interpersonal trust. Personality and Individual Differences, 32, 375-382. https:// doi.org/10.1016/S0191-8869(00)00224-5

Beierlein, C., Kemper, C. J., Kovaleva, A., \& Rammstedt, B. (2014a). Interpersonales Vertrauen (KUSIV3) [Interpersonal Trust (KUSIV3)]. Zusammenstellung sozialwissenschaftlicher Items und Skalen. https://doi.org/10.6102/zis37

Beierlein, C., Kemper, C. J., Kovaleva, A., \& Rammstedt, B. (2014b). Political Efficacy Kurzskala (PEKS) [Political Efficacy Short Scale (PEKS)]. Zusammenstellung sozialwissenschaftlicher Items und Skalen. https://doi.org/10.6102/zis34

Beierlein, C., Kovaleva, A., Kemper, C. J., \& Rammstedt, B. (2014). Allgemeine Selbstwirksamkeit Kurzskala (ASKU) [General Self-Efficacy Short Scale (ASKU)]. Zusammenstellung sozialwissenschaftlicher Items und Skalen. https://doi.org/10. $6102 /$ zis35

Beierlein, C., Kovaleva, A., László, Z., Kemper, C. J., \& Rammstedt, B. (2015). Kurzskala zur Erfassung der Allgemeinen Lebenszufriedenheit (L-1) [Short scale for measuring general life satisfaction (L-1)]. Zusammenstellung sozialwissenschaftlicher Items und Skalen. https://doi.org/10.6102/zis229

Beilmann, M., Kööts-Ausmees, L., \& Realo, A. (2018). The relationship between social capital and individualism-collectivism in Europe. Social Indicators Research, 137, 641-664. https://doi.org/10.1007/s11205-017-1614-4

Benson, M., \& Rochon, T. R. (2004). Interpersonal trust and the magnitude of protest: A micro and macro level approach. Comparative Political Studies, 37, 435-457. https://doi.org/10.1177/0010414003262900

Breyer, B. (2015). Left-Right Self-Placement (ALLBUS). Zusammenstellung sozialwissenschaftlicher Items und Skalen. https://doi.org/10.6102/zis83

Brosseau-Liard, P. E., \& Savalei, V. (2014). Adjusting incremental fit indices for nonnormality. Multivariate Behavioral Research, 49, 460-570. https://doi.org/ 10.1080/00273171.2014.933697

Brosseau-Liard, P. E., Savalei, V., \& Li, L. (2012). An investigation of the sample performance of two nonnormality corrections for RMSEA. Multivariate Behavioral Research, 47, 904-930. https://doi.org/10.1080/00273171.2012. 715252

Bulloch, S. L. (2010). Men and women's interpersonal trust: An empirical investigation (Doctoral dissertation, University of Surrey, Guildford, United Kingdom). Retrieved from http://epubs.surrey.ac.uk/842909/

Bulloch, S. L. (2013). Seeking construct validity in interpersonal trust research: A proposal on linking theory and survey measures. Social Indicators Research, 113, 1289-1310. https://doi.org/10.1007/s11205-012-0139-0

Carifio, J., \& Perla, R. J. (2007). Ten common misunderstandings, misconceptions, persistent myths and urban legends about Likert scales and Likert response formats and their antidotes. Journal of Social Sciences, 3, 106-116. https://doi. org/10.3844/jssp.2007.106.116

Chen, F. F. (2007). Sensitivity of goodness of fit indexes to lack of measurement invariance. Structural Equation Modeling: A Multidisciplinary Journal, 14, 464504. https://doi.org/10.1080/10705510701301834 
Cohen, J. (1992). A power primer. Psychological Bulletin, 112, 155-159. https://doi. org/10.1037/0033-2909.112.1.155

Costa, P. T., McCrae, R., \& Dye, D. A. (1991). Facet scales for Agreeableness and Conscientiousness: A revision of the NEO Personality Inventory. Personality and Individual Differences, 12, 887-898. https://doi.org/10.1016/01918869(91)90177-D

Cronbach, L. J. (1951). Coefficient alpha and the internal structure of tests. Psychometrika, 16, 297-334. https://doi.org/10.1007/BF02310555

Doll, E., Nießen, D., Schmidt, I., Rammstedt, B., \& Lechner, C. M. (2020). The General Self-Efficacy Short Scale-3 (GSE-3): An English-language adaptation. Manuscript in preparation.

European Social Survey (2016). ESS round 8 source questionnaire. ESS ERIC Headquarters c/o City University London.

Evans, A., \& Revelle, W. (2008). Survey and behavioral measurements of interpersonal trust. Journal of Research in Personality, 42, 1585-1593. https:// doi.org/10.1016/j.jp.2008.07.011

Fairbrother, M., \& Martin, I. W. (2013). Does inequality erode social trust? Results from multilevel models of US states and counties. Social Science Research, 42, 347-360. https://doi.org/10.1016/j.ssresearch.2012.09.008

Feng, Z., Vlachantoni, A., Liu, X., \& Jones, K. (2016). Social trust, interpersonal trust and self-rated health in China: A multi-level study. International Journal for Equity in Health, 15, 180. Retrieved from http://search.ebscohost.com/login. aspx? direct $=$ true\&db=cmedm\&AN=27825358\&site=ehost-live

Fetchenhauer, D., \& Dunning, D. (2009). Do people trust too much or too little? Journal of Economic Psychology, 30, 263-276. https://doi.org/10.1016/j.joep. 2008.04.006

Groskurth, K., Nießen, D., Rammstedt, B., \& Lechner, C. M. (2020). An Englishlanguage adaptation and validation of the Political Efficacy Short Scale (PESS). Manuscript submitted for publication. https://doi.org/10.1186/s42409020-00018-z

Halamandaris, K. F., \& Power, K. G. (1997). Individual differences, dysfunctional attitudes, and social support: A study of the psychosocial adjustment to university life of home students. Personality and Individual Differences, 22, 93104. https://doi.org/10.1016/S0191-8869(96)00175-4

Harkness, J. A. (2003). Questionnaire translation. In J. A. Harkness, F. van de Vijver, \& P. P. Mohler (Eds.), Cross-cultural survey methods (pp. 35-56). Hoboken, NJ: Wiley.

Jovanović, V. (2016). Trust and subjective well-being: The case of Serbia. Personality and Individual Differences, 98, 284-288. https://doi.org/10.1016/j. paid.2016.04.061

Kasperson, R. E., Golding, D., \& Tuler, S. (1992). Social distrust as a factor in siting hazardous facilities and communicating risks. Journal of Social Issues, 48, 161187. https://doi.org/10.1111/j.1540-4560.1992.tb01950.x

Kemper, C. J., Beierlein, C., Bensch, D., Kovaleva, A., \& Rammstedt, B. (2014). Soziale Erwünschtheit-Gamma (KSE-G) [Social Desirability-Gamma Short Scale (KSE-G)]. Zusammenstellung sozialwissenschaftlicher Items und Skalen. https:// doi.org/10.6102/zis186

Kemper, C. J., Beierlein, C., Kovaleva, A., \& Rammstedt, B. (2014). Skala Optimismus-Pessimismus-2 (SOP2) [Optimism-Pessimism Short Scale-2 (SOP2)]. Zusammenstellung sozialwissenschaftlicher Items und Skalen. https:// doi.org/10.6102/zis185

Kemper, C. J., \& Menold, N. (2014). Nuisance or remedy? The utility of stylistic responding as an indicator of data fabrication in surveys. Methodology: European Journal of Research Methods for the Behavioral and Social Sciences, 10, 92-99. https://doi.org/10.1027/1614-2241/a000078

Kemper, C. J., Trapp, S., Kathmann, N., Samuel, D. B., \& Ziegler, M. (2019). Short versus long scales in clinical assessment: Exploring the trade-off between resources saved and psychometric quality lost using two measures of obsessive-compulsive symptoms. Assessment, 26, 767-782. https://doi.org/10. 1177/1073191118810057

Koller, M. (1992). Sozialpsychologie des Vertrauens: Ein Überblick über theoretische Ansätze [Social psychology of trust: An overview of theoretical approaches]. Psychologische Beiträge, 34, 265-276.

Kopp, T., \& Schuler, H. (2003). Vertrauen gegenüber Vorgesetzten und Akzeptanz von Entgeltsystemen [Trust in supervisors and acceptance of remuneration systems]. Zeitschrift für Personalpsychologie, 2, 182-192. https://doi.org/10. 1026//1617-6391.2.4.182

Kovaleva, A., Beierlein, C., Kemper, C. J., \& Rammstedt, B. (2014). InternaleExternale-Kontrollüberzeugung-4 (IE-4) [Internal-External Locus of Control-4 (IE-4)]. Zusammenstellung sozialwissenschaftlicher Items und Skalen. https://doi. org/10.6102/zis184
Krampen, G. (2000). Handlungstheoretische Persönlichkeitspsychologie: Konzeptuelle und empirische Beiträge zur Konstrukterhellung [Action-theory personality psychology: Conceptual and empirical contributions for the elaboration of the construct] (2nd ed.). Göttingen: Hogrefe.

Krampen, G., \& Hank, P. (2004). Die Vertrauens-Trias: Interpersonales Vertrauen, Selbstvertrauen und Zukunftsvertrauen in der psychologischen Theoriebildung und Forschung [The trust triad: Interpersonal trust, self-trust, and trust in the future as topics of psychological theory building and research]. Report Psychologie, 11, 666-677.

Krampen, G., Viebig, J., \& Walter, W. (1982). Entwicklung einer Skala zur Erfassung dreier Aspekte von sozialem Vertrauen [Development of a scale to assess three aspects of social trust]. Diagnostica, 28, 242-247.

Krosnick, J. A., \& Fabrigar, L. R. (1997). Designing rating scales for effective measurement in surveys. In L. Lyberg, P. Biemer, M. Collins, E. De Leeuw, C. Dippo, N. Schwarz, \& D. Trewin (Eds.), Survey measurement and process quality (pp. 141-164). New York, NY: Wiley.

Lechner, C. M., Danner, D., \& Rammstedt, B. (2019). Grit (effortful persistence) can be measured with a short scale, shows little variation across socio-demographic subgroups, and is associated with career success and career engagement. PLoS One, 14, e0224814. https://doi.org/10.1371/journal.pone.0224814

Lechner, C. M., Partsch, M. V., Danner, D., \& Rammstedt, B. (2019). Individual, situational, and cultural correlates of acquiescent responding: Toward a unified conceptual framework. British Journal of Medical and Statistical Psychology, 72, 426-446. https://doi.org/10.1111/bmsp.12164

Lechner, C. M., \& Rammstedt, B. (2015). Cognitive ability, acquiescence, and the structure of personality in a sample of older adults. Psychological Assessment, 27, 1301-1311. https://doi.org/10.1037/pas0000151

Liu, J., Rau, P.-L. P., \& Wendler, N. (2015). Trust and online information-sharing in close relationships: A cross-cultural perspective. Behavior \& Information Technology, 34, 363-374. https://doi.org/10.1080/0144929X.2014.937458

Lundmark, S., Gilljam, M., \& Dahlberg, S. (2016). Measuring generalized trust: An examination of question wording and the number of scale points. Public Opinion Quarterly, 80, 26-43. https://doi.org/10.1093/poq/nfv042

Massari, D. J., \& Rosenblum, D. C. (1972). Locus of control, interpersonal trust and academic achievement. Psychological Reports, 31, 355-360. https://doi.org/10. 2466/pro.1972.31.2.355

McDonald, R. P. (1999). Test theory: A unified treatment. Mahwah, NJ: Lawrence Erlbaum Associates. https://doi.org/10.1111/j.2044-8317.1981.tb00621.x

Meade, A. W., \& Craig, S. B. (2012). Identifying careless responses in survey data. Psychological Methods, 17, 437-455. https://doi.org/10.1037/a0028085

Mealy, M., Stephan, W. G., Mhaka-Mutepfa, M., \& Alvadoro-Sanchez, L. (2015). Interpersonal trust in Ecuador, the United States, and Zimbabwe. CrossCultural Research, 49, 393-421. https://doi.org/10.1177/1069397115591479

Munir, Y., Khan, S.-U.-R., Sadiq, M., Ali, I., Hamdan, Y., \& Munir, E. (2016). Workplace isolation in pharmaceutical companies: Moderating role of self-efficacy. Social Indicators Research, 126, 1157-1174. https:/doi.org/10.1007/s11205-015-0940-7

Naef, M., \& Schupp, J. (2009). Measuring trust: Experiments and surveys in contrast and combination (SOEPpapers on Multidisciplinary Panel Data Research No. 167). Berlin: DIW Berlin.

Nießen, D., Groskurth, K., Kemper, C. J., Rammstedt, B., \& Lechner, C. M. (2020). An English-language adaptation of the Optimism-Pessimism Short Scale-2 (SOP2). Manuscript in preparation.

Nießen, D., Groskurth, K., Rammstedt, B., \& Lechner, C. M. (2020a). An Englishlanguage adaptation of the General Life Satisfaction Short Scale (L-1). Zusammenstellung sozialwissenschaftlicher Items und Skalen (ZIS). https://doi. org/10.6102/zis284

Nießen, D., Groskurth, K., Rammstedt, B., \& Lechner, C. M. (2020b). An Englishlanguage adaptation of the Internal-External Locus of Control Short Scale-4 (IE-4). Manuscript in preparation.

Nießen, D., Partsch, M. V., Kemper, C. J., \& Rammstedt, B. (2019). An Englishlanguage adaptation of the Social Desirability-Gamma Short Scale (KSE-G). Measurement Instruments for the Social Sciences, 1, 2. https://doi.org/10.1186/ s42409-018-0005-1

Norman, G. (2010). Likert scales, levels of measurement and the "laws" of statistics. Advances in Health Sciences Education, 15, 625-632. https://doi.org/ 10.1007/s10459-010-9222-y

OECD (2017). OECD guidelines on measuring trust. Paris: OECD Publishing. https:// doi.org/10.1787/9789264278219-en

Omodei, M. M., \& McLennan, J. (2000). Conceptualizing and measuring global interpersonal mistrust-trust. Journal of Social Psychology, 140, 279-294. https://doi.org/10.1080/00224540009600471 
Perunovic, M. (2008). Agreeableness and close relationships: Is it trust that really matters? Dissertation Abstracts International: Section B: The Sciences and Engineering, 68, 8447. Retrieved from http://search.ebscohost.com/login. aspx?direct=true\&db=psyh\&AN=2008-99120-166\&site=ehost-live

Putnam, R. D. (1993). Making democracy work: Civic traditions in modern Italy. Princeton, NJ: Princeton University Press.

Putnam, R. D. (1995). Bowling alone: America's declining social capital. Journal of Democracy, 6, 65-78. https://doi.org/10.1007/978-1-349-62397-6_12

Putnam, R. D. (2000). Bowling alone: The collapse and revival of American community. New York, NY: Simon \& Schuster. https://doi.org/10.1145/358916. 361990

Rammstedt, B., Danner, D., Soto, C. J., \& John, O. P. (2020). Validation of the short and extra-short forms of the Big Five Inventory-2 (BFI-2) and their German adaptations. European Journal of Psychological Assessment, 36, 149-161. https://doi.org/10.1027/1015-5759/a000481

Raykov, T. (1997). Estimation of composite reliability for congeneric measures. Applied Psychological Measurement, 21, 173-184. https://doi.org/10.1177/ 01466216970212006

Reeskens, T., \& Hooghe, M. (2008). Cross-cultural measurement equivalence of generalized trust. Evidence from the European Social Survey (2002 and 2004) Social Indicators Research, 85, 515-532. https://doi.org/10.1007/s11205-0079100-z

Rhemtulla, M., Brosseau-Liard, P. É., \& Savalei, V. (2012). When can categorical variables be treated as continuous? A comparison of robust continuous and categorical SEM estimation methods under suboptimal conditions. Psychological Methods, 17, 354-373. https://doi.org/10.1037/a0029315

Rose, N., Wagner, W., Mayer, A., \& Nagengast, B. (2019). Model-based manifest and latent composite scores in structural equation models. Collabra: Psychology, 5, 9. https://doi.org/10.1525/collabra.143

Rotter, J. B. (1967). A new scale for the measurement of interpersonal trust. Journal of Personality, 35, 651-655. https://doi.org/10.1111/j.1467-6494.1967. tb01454.x

Rotter, J. B. (1971). Generalized expectancies for interpersonal trust. American Psychologists, 26, 443-452. https://doi.org/10.1037/h0031464

Schiffman, L., Thelen, S. T., \& Sherman, E. (2010). Interpersonal and political trust: Modeling levels of citizens' trust. European Journal of Marketing, 44, 369-381. https://doi.org/10.1108/03090561011020471

Schneider, I. K., Konijn, E. A., Righetti, F., \& Rusbult, C. (2011). A healthy dose of trust: The relationship between interpersonal trust and health. Personal Relationships, 18, 668-676. https://doi.org/10.1111/j.1475-6811.2010.01338.x

Schweer, M. K. W. (2006). Vertrauen [Trust]. In D. H. Rost (Ed.), Handwörterbuch Pädagogische Psychologie [Pocket dictionary of pedagogic psychology] (3rd ed., pp. 848-852). Weinheim: Beltz.

Schyns, P., \& Koop, C. (2010). Political distrust and social capital in Europe and the USA. Social Indicators Research, 96, 145-167. https://doi.org/10.1007/s11205009-9471-4

Soto, C. J., \& John, O. P. (2017). Short and extra-short forms of the Big Five Inventory-2: The BFI-2-S and BFI-2-XS. Journal of Research in Personality, 68, 69-81. https://doi.org/10.1016/j.jp.2017.02.004

Stadelmann-Steffen, I., \& Freitag, M. (2007). Der ökonomische Wert sozialer Beziehungen [The economic value of social relations]. Kölner Zeitschrift für Soziologie und Sozialpsychologie, 47, 294-320.

Stimpson, T. F. D. V., \& Maughan, M. R. C. (1978). Some correlates of trust. The Journal of Psychology: Interdisciplinary and Applied, 99, 103-108. https://doi. org/10.1080/00223980.1978.9921447

Sullivan, J. L., \& Transue, J. E. (1999). The psychological underpinnings of democracy: A selective review of research on political tolerance, interpersonal trust, and social capital. Annual Review of Psychology, 56, 625650. https://doi.org/10.1146/annurev.psych.50.1.625

Takahashi, T., Ikeda, K., Ishikawa, M., Kitamura, N., Tsukasaki, T., Nakama, D., \& Kameda, T. (2005). Interpersonal trust and social stress-induced cortisol elevation. Neuroendocrinology, 16, 197-199. https://doi.org/10.1097/00001756200502080-00027

Thurber, S., \& Friedli, R. (1976). Internal-external control, interpersonal trust, and the motive to avoid success in college women. The Journal of Psychology: Interdisciplinary and Applied, 92, 141-143. https://doi.org/10.1080/00223980. 1976.9921347

Twenge, J. M., Campbell, W. K., \& Carter, N. T. (2014). Declines in trust in others and confidence in institutions among American adults and late adolescents, 1972-2012. Psychological Science, 25, 1914-1923. https://doi.org/10.1177/ 0956797614545133
Van der Veld, W. M., \& Saris, W. E. (2011). Causes of generalized trust. In E. Davidov, P. Schmidt, \& J. Billiet (Eds.), Cross-cultural analysis: Methods and applications (pp. 207-248). New York, NY: Routledge/Taylor \& Francis Group.

Vandenberg, R. J., \& Lance, C. E. (2000). A review and synthesis of the measurement invariance literature: Suggestions, practices, and recommendations for organizational research. Organizational Research Methods, 3, 4-70. https://doi.org/10.1177/109442810031002

Weijters, B., Baumgartner, H., \& Schillewaert, N. (2013). Reversed item bias: An integrative model. Psychological Methods, 18, 320-334. https://doi.org/10. 1037/a0032121

Widaman, K. F., \& Reise, S. P. (1997). Exploring the measurement invariance of psychological instruments: Applications to the substance use domain. In K. J. Bryant, M. Windle, \& S. G. West (Eds.), The science of prevention: Methodological advances from alcohol and substance abuse research (pp. 281324). Washington, DC: American Psychological Association.

Wrightsman, L. S. (1991). Interpersonal trust and attitudes toward human nature. In J. P. Robinson, P. R. Shaver, \& L. S. Wrightsman (Eds.), Measure of social psychological attitudes, Vol. 1. Measures of personality and social psychological attitudes (pp. 373-412). San Diego, CA: Academic Press. https://doi.org/10. 1016/B978-0-12-590241-0.50012-5

Zinchenko, Y. P., Zotova, O. Y., \& Tarasova, L. V. (2017). Specifics of interpersonal trust among people with different gender identities. Psychology in Russia: State of the Art, 10, 134-148. https://doi.org/10.11621/pir.2017.0209

\section{Publisher's Note}

Springer Nature remains neutral with regard to jurisdictional claims in published maps and institutional affiliations.
Ready to submit your research? Choose BMC and benefit from:

- fast, convenient online submission

- thorough peer review by experienced researchers in your field

- rapid publication on acceptance

- support for research data, including large and complex data types

- gold Open Access which fosters wider collaboration and increased citations

- maximum visibility for your research: over $100 \mathrm{M}$ website views per year

At BMC, research is always in progress.

Learn more biomedcentral.com/submissions 